\title{
TOURISMUS GENERIERENDE ROLLE DES LOKALEN KULTURELLEN UND ÖKOLOGISCHEN ERBGUTES - AM BEISPIEL VON ORADEA/ NAGYVÁRAD/GROSSWARDEIN UND EGER/ERLAU
}

\author{
Verók, Attila
}

Zwischen Oradea/Nagyvárad/Großwardein (RO) und Eger/Erlau (HU) bestand eine enge Beziehung in der Geschichte der vergangenen beinahe tausend Jahre vorwiegend hinsichtlich Kirchen-, Kultur- und Wirtschaftsgeschichte, aber auch in anderen Bereichen des alltäglichen Lebens. Diese Interdependenz änderte sich bis heute kaum, ausschließlich die Dominanz des Charakters der Verbindungen gestaltete sich um. Beide Städte und ihre Agglomerationsräume verfügen über eine reichhaltige historische Vergangenheit und natürliche Ressourcen, was als Grundlage zur Ausbeutung des lokalen kulturellen und ökologischen Erbgutes zwecks Tourismus dient. Aus der Einstellung in nationalökonomischer Hinsicht und der wesentlich verschiedenen ethnischen Umgebung ergab sich eine divergente touristische Verwendung mit Bezug auf die örtlichen Erbschaftselemente.

In diesem Beitrag werden auf komparative Weise diejenigen Faktoren vorgestellt, die durch Dissemination des Patrimoniums, das die lokalen Gemeinschaften aufrechterhält, eine belebende und generierende Wirkung auf Tourismus und Geschäftsumsatz erreichen oder erreichen können. An dieser Stelle werden auch die Fragen der sich auf die Personen der eigenen Nationalität richtenden und von der Nationalität unabhängigen Tourismuszweige bzw. das Problem der sog. „Ersitzung” des kulturellen Erbgutes in einem Koordinatensystem von einer Mehrheit und einer Minderheit erörtert.

Schlüsselwörter: lokales Erbgut - kulturelles Erbgut - ökologisches Erbgut - Tourismus - Oradea/Nagyvárad/Großwardein (RO) - Eger/Erlau (HU)

JEL: Z10

DOI: $10.33032 /$ acr.2020.10.1.189 


\section{THE CAPABILITY OF THE CULTURAL AND ECOLOGICAL HERITAGE OF ORADEA/NAGYVÁRAD/GROSSWARDEIN AND EGER/ERLAU TO PROMOTE TOURISM}

The historical, religious, cultural, and economic ties between Oradea/Nagyvárad/ Großwardein (RO) and Eger/Erlau (HU) had been formed almost 1000 years ago. While throughout the centuries the main aspects of this interdependent relationship did not substantially change, the dominant forms of cooperation have undergone periodic modifications. Although both cities and their catchment area have a rich historical past and possess significant natural resources facilitating the utilization of the local cultural and ecological heritage for tourism purposes, the varying economic and business attitudes along with the significantly different ethnic composition resulted in differing ways of achieving that objective. Relying on a comparative approach, I will explore those factors that can boost tourism and generate increased revenues via the dissemination of the patrimony preserved by local communities. Special attention will be paid to ethnicityspecific tourism, that is tourism oriented to the needs of one's own ethnicity, and nonethnicity dependent tourism along with the problem of the misappropriation of the specific heritage either on the part of the given minority or majority.

Key terms: local heritage - cultural heritage - ecological heritage - tourism - Oradeal Nagyvárad/Großwardein (RO) - Eger/Erlau (HU)

JEL: Z10 


\section{Einführung}

In diesem Beitrag werden zwei Siedlungen im Donau-Karpatenraum, einst beides dem Königreich Ungarn gehörig (heute: Großwardein in Rumänien und Erlau in Ungarn) aus der Sicht der auszunutzenden Möglichkeiten mit Bezug auf das kulturelle Erbgut in groben Umrissen parallel dargestellt. Die beiden Städte wurden neben der Tatsache, dass der Autor in beiden Ortschaften aktiv täig ist und die hiesigen ungarischsprachigen Universitäten seit langem miteinander zusammenarbeiten, bewusst ausgewählt, wozu die enge Verflechtung der Geschichte zweier Regionen, die durch ihre bedeutendsten Residenzstädte versinnbildlicht wird, als Grundlage angenommen worden ist. Die historische Interdependenz kristallisiert sich in vielen Phänomenen heraus, aus denen an dieser Stelle ausschließlich etliche erörtert werden. Als Methoden zur Analyse werden hier (kultur)historische und volkswirtschaftliche Ausführungen verwendet.

\section{Historische Interdependenz}

Sowohl Großwardein (ungefähr 200000 Einwohner) als auch Erlau (beinahe 54000 Einwohner) und ihre Umgebungen gelten seit uralten Zeiten als dicht bevölkerte Siedlungen, zwischen denen regelmäßige Beziehungen archäologisch nachweisbar sind. (Cséplő, 1901; Reiszig, 1901; Nagy, 1978; Vahot ${ }^{2}$ 1985)

Die beiden Städte fungierten seit Anfang des 11. Jahrhunderts als Bischofssitze: Erlau seit etwa 1004 unter der Regierung des Königs Stefan I. (1000-1038), Komitat Bihar seit 1010, wo 1091 der zentrale Ort unter der Regierung des Königs Ladislaus I. (1077-1095) Großwardein geworden ist. Das Gebiet der Großwardeiner Diözese bildete einmal einen Teil der stattlichen Erlauer Diözese, also ihre Beziehung offenbarte sich einmal auch in Form einer gemeinsamen Kirchenverwaltung. (Bunyitay, 1883-84; Kristó, 1988)

Beide Siedlungen sind als Begräbnistätten ungarischer Könige und Königinnen bekannt. In Großwardein sind nach dem Jahr 1113 König Ladislaus I., 1131 König Stefan II. (1116-1131), 1295 Königin Fennena, Frau des Königs Andreas III. (12901301), 1319 Königin Beatrix von Luxemburg, Frau des Königs Karl I. (1308-1342), 1395 Königin Maria I. (1382-1395) und 1437 König bzw. deutsch-römischer Kaiser Sigismund von Luxemburg (1387-1437) bestattet worden. Dank diesen Königstableaus steht die heute in Rumänien befindliche Stadt nach Székesfehérvár/ Stuhlweißenburg (HU) auf dem zweiten Platz der bedeutendsten Begräbnisstätten, wo ungarische Herrscher und Herrscherinnen in großer Anzahl beerdigt worden sind. Dementgegen wurde in Erlau nur ein einziger ungarischer König aus dem Haus der Arpaden, namens Emerich (1196-1204) in einer der größten Domkirchen Europas in der Burg von Erlau begraben. (Hankó, ${ }^{2} 2004$ ) 
Das kirchliche - nicht nur das katholische, sondern teilweise auch das protestantische - Erbgut hat sich während der letzten zehn Jahrhunderte zwischen Großwardein und Erlau verflochten. Zahlreiche Geistliche, Kanoniker, Äbte, bei der Kirche angestellte Künstler, Handwerkermeister usw. fanden aus Komitat Bihar kommend ihren Karrierewege in Erlau, wobei eine Gegenrichtung (aus Erlau nach Großwardein) nur selten identifiziert werden kann. (Bunyitay, 1883; Sugár, 1984; Kovács, 1987)

Die engste, unzertrennliche Beziehung zwischen den beiden Städten kann im Bereich der Kulturgeschichte aufgewiesen werden. Hier geht es u.a. um die unterschiedlichsten Wechselwirkungen von der Unterrichtsgeschichte und typographischen Tätigkeit zahlreicher Drucker über die medizinischen Praxen bedeutender Ärzte bis hin zu den dauerhaften Werken verschiedener Wissenschaftler, Künstler, Baumeister, Architekten und Kunsthistoriker. (Fraknói, 1888; Gyalókay, 1937; Szmrecsányi, 1937; Tarr, 1977; Péter, 1998; Emődi, 2010a; Emődi, 2010b; Boka - Emődi, 2016; Emődi 2017)

Die genannten Gebiete stellen nur einen Teil der weitverzweigten Beziehungen zwischen Großwardein und Erlau dar. Ich halte es hier für nicht nötig, auf jedes Detail einzugehen. Die geschilderten Beispiele zeigen schon überzeugend, dass die Interdependez in der geschichtlichen Vergangenheit bestand und teilweise immer noch besteht. Eine kurze Anmerkung noch zum Themenkreis. Im Laufe der Geschichte ist eine gesellschaftliche Migration hinsichtlich der fokussierten geographischen Konstellation in zwei Richtungen zu beobachten, wobei die Strömung von Menschen in Richtung aus Großwardein nach Erlau, d.h. aus dem Osten nach Westen immer stärker als in Gegenrichtung war.

\section{Touristische Anziehungskräfte}

Neben der historischen Interdependenz können sowohl in der Vergangenheit als auch in der Gegenwart Attraktionen in Betracht gezogen werden, die in beiden Städten als parallel bestehende touristische Anziehungskräfte dienen konnten und können. Diese vorrangig kulturell bedingten Faktoren sind bei entsprechender Behandlung ohne Weiteres geeignet, den beiden Regionen und Ländern regionsspezifischen und gesamtwirtschaftlichen Nutzen zu erzielen.

\section{Kirchliches Erbgut}

Die von den Ungarn St.-Ladislaus-Kathedrale genannte römisch-katholische Kirche in Großwardein stellt die größte Barockkirche in Rumänien dar. (Bunyitay, 1880) In Erlau steht die zweitgrößte römisch-katholische Basilika Ungarns, geweiht zu Ehren von St.-Michael- und St.-Johannes, gebaut in klassizistischem Stil. (Voit, 1934) 
Beide Kirchen locken eine Vielzahl von Gläubigen, Pilgern und bautechnisch bzw. kunsthistorisch interessierten Touristen mit oder ohne Bekenntnis an.

\section{Gebautes Erbgut - Wallfahrtsorte}

Inmitten der Stadt, umgeben von neuen Einfamilien- und Blockhäusern, steht die Burg von Großwardein, gebaut im 11. Jahrhundert, ergänzt und erneut allmählich bis zum 21. Jahrhundert. (Kiss, ${ }^{2} 1990$ ) Auf einer Höhe über der Stadt erhebt sich die Burg von Erlau, gebaut im frühen 11. Jahrhundert, ergänzt und erneut allmählich bis zum 21. Jahrhundert. (Sugár, ${ }^{3} 2002$ ) Beide Burgen spielten in der Politik- und Militärgeschichte eine bedeutende Rolle. Im Falle von Erlau sticht das Jahr 1552 durch einen glorreichen Sieg gegen die Türken hervor, der den sog. "Kultus der Burg von Erlau" hervorrief. Dieser Kultus wurde jahrhundertelang am Leben erhalten und dient auch heutzutage als Grundlage zur touristischen Attraktionen in der Burg. (Petercsák, 2002) Dieser Kultus erreichte 1901 ihren Höhepunkt, als der Schriftsteller Géza Gárdonyi seinen Roman mit dem Titel Die Sterne von Erlau (Egri csillagok) veröffentlicht hat. Der Triumphzug des Romans dauert heute noch als Pflichtlektüre in der Grundschule für sämtliche Schülerinnen und Schüler in Ungarn. Das Buch gilt heute als einer der bekanntesten literarischen Texte Ungarns, also es verstärkt den Ruhm von Erlau immer noch und macht die Stadt zu einem der Hauptzielpunkte des Tourismus in Ungarn. Als denkwürdiges Datum in der Geschichte der Burg von Großwardein kann das Jahr 1660 erwähnt werden. In diesem Jahr haben die Türken die Burg erobert, damit entstand das letzte türkische Vilajet im Donau-Karpatenraum. (Balla - Lakatos, 2013) Beide Geschichten sind in Hinsicht auf den Tourismus Bestseller geworden: Jedes Jahr zu Sommerzeit werden sowohl in Großwardein als auch in Erlau Freilichttheaterspiele vorgeführt, wo auf der einen Bühne die siegreiche, auf der anderen Bühne aber die trübe Geschichte vor breitem Publikum mit großem Erfolg wieder lebendig gemacht wird.

Die oben erwähnten Anziehungskräfte wie Kathedralen und Burgen können auch eine Rolle als Wallfahrtsorte spielen. Die königlichen Begräbnistätten, der Kultus bezüglich der römisch-katholischen und der protestantischen Oberhirten in Großwardein (Fleisz, 2003) und der Kultus bezüglich der römisch-katholischen Bischöfe und Erzbischöfe in Erlau (Löffler, ${ }^{2} 2002$ ), ferner die historischen Gedänkstätten im Zusammenhang mit den Burgen können in profanem und/oder sakralem Sinne wirtschaftlich und kulturell ausgenutzt werden.

$\mathrm{Zu}$ diesem Punkt gehört noch die Frage des gebauten Erbgutes der Innenstädte. Beide Städten haben seit ihren Anfängen eine multikulturelle Bevölkerung, was eine zusammengesetzte, historische Architektur und "Baustilkavalkade" voraussetzt. In Erlau stechen Barock (Gebäude in der Innenstadt, Minoritenkirche auf dem Hauptplatz), Zopfstil (Lyzeum, d.h. das historische Gebäude der Universität) und Klassizismus (Basilika) ins Auge, während in Großwardein der Jugendstil (Hauptstraße, 
Bemerplatz, Schwarzadler-Palast, Justizpalast) dominiert. (Haris - Somorjay - Bardoly, 2005) In der rumänischen Stadt herrschte eine starke bürgerliche Kultur zur Zeit der österreichisch-ungarischen Monarchie und hinterließ gebaute Monumente des christlich-jüdischen Großbürgertums, der rumänischen Nationalarchitektur und der byzantinisch-orthodoxen Kirchenkultur (vor etwa hundert Jahren). (Dukrét - Péter, 2016) Im Gegenteil dazu können die Spuren einer bürgerlichen Architektur der Wende vom 19. zum 20. Jahrhundert in Erlau kaum entdeckt werden.

In den letzten Jahrzehnten können im Fall beider Städte von einer "Renaissance" der Innenstädte reden. Die Rekonstruktionsvorhaben lösten überall heftige Diskussionen und/oder Proteste von der Seite der Stadtbevölkerung aus, die in Großwardein auch mit einem Streit zwischen den rumänischen und den ungarischen Nationalitäten verbunden waren und sind. In Erlau entstanden funktionale öffentliche Räume und Plätze in der letzten Zeit dank der Neuplanung der Innenstadt, was eine starke Anziehungskraft auf den Tourismus ausübt. Im Fall von Großwardein kann von einer gleichen Erscheinung, abgesehen vom Hauptplatz, kaum die Rede sein.

Beide Städte verfügen über ein kommunistisch-sozialistisches, gebautes Erbgut, das in Hinsicht auf Tourismus auch auszunutzen scheint. Es gibt aber einen großen Unterschied zwischen der rumänischen und der ungarischen gebauten Wirklichkeit. In Großwardein herrscht überall eine Plattenbauwüste von der Innenstadt bis hin $\mathrm{zu}$ den Vororten und kann eine allgemeine und strategische Absicht zur Homogenisierung von Wohngebäuden erfahren werden. In Erlau findet man Blockhäuser und Plattenbauwohnungen nur in geringerer Anzahl und ausschließlich in den Vorstädten, in der historischen Innenstadt nicht, und hier kann man von keinem Homogenisierungsprozess reden.

\section{Literarische Tradition}

Ein Teil der Gäste, die die Städte besuchen, interessiert sich für die literarische Kulturtradition, die in beiden Siedlungen sehr stark gegenwärtig ist. Die Namen von Endre Ady (1877-1919), Gyula Krúdy (1878-1933), Gyula Juhász (1883-1937) und Géza Tabéry (1890-1958) verknüpfen sich eindeutig mit dem ehemaligen pulsierenden Kulturleben von Großwardein, dem "Paris am Ufer der Kreisch” (Ady). (Pomogáts, 2013) Unter den namhaftesten Vertretern der Belletristik in Erlau, “im ungarischen Athen” (Imre Madách) sind Géza Gárdonyi (1863-1922) und Sándor Bródy (1863-1924) zu nennen. (Hovanyecz, 2005) Der oben erwähnte Roman von Gárdonyi im Zusammenhang mit der Burg und das Gárdonyi-Haus locken jedes Jahr zehntausende von Besuchern an.

Sowohl in Großwardein (Szigligeti-Theater) als auch in Eger (Gárdonyi-Theater, Harlekin Puppentehater) bieten berühmte Theater hochqualitative kulturelle Programme und zu Sommerzeiten erwarten auch Freilichtbühnen ihre Zuschauer. 


\section{Badekultur}

Dank der günstigen geographischen Lage kann man im Fall beider Städte und Umgebung von einem bedeutenden und entwickelten Badewesen reden. Das Baden in kaltem, aber vor allem in warmem Wasser dient heutzutage in erster Linie nicht mehr der Reinigung, sondern vielmehr der Förderung der Gesundheit und des Wohlbefindens. Zur Badekultur gehören auch die Schwimmbäder, die hauptsächlich zu Sportzwecken dienen. Was das dichte Vorkommen der Heilbäder anbelangt, steht Erlau am ersten Platz gegenüber Großwardein. In Erlau gibt es zwei Schwimmbäder (nach Aladár Bitskey und István Bárány benannt), zwei Freibäder (Stadtstrand mit Thermalbad, türkisches Bad aus dem 17. Jahrhundert) und vier Badeorte in unmittelbarer Nähe der Stadt (Bogács, Demjén, Egerszalók, Mezőkövesd). (Bede, 2014) Großwardein verfügt über einen Aquapark (Nymphaea) und zwei Thermalbäder (Felix-Bad und Bischofsbad) in der Agglomeration. (Péter, 2009) Durch die Wellness-Abteilungen der Hotels kann das Angebot an Badekultur noch größer und abwechslungsreicher sein, aber diese Erholungsmöglichkeiten wurden hier nicht in Betracht gezogen.

\section{Wein- und Gastrokultur}

Nach der politischen Wende (1989) begannen sich Weinbau und Weinproduktion in Richtung Qualität statt Quantität zu entwickeln. Beide ehemaligen sozialistischen Länder hatten in diesem Bereich viel zu tun und nachzuholen. Die Grundfläche des Biharer Teils der Weinregion Érmellék beträgt etwa 250 Hektar (Produktionszentrum Bihardiószeg/Diosig). Die berühmteste Weinsorte heißt hier Bakator (Weißwein). (Duka, 2005; Fazekas, 2020) Über ein wesentlich größeres Anbaugebiet verfügt die Weinregion Erlau: Die ganze Weinregion hat eine Gesamtfläche von 22160 Hektar, aber davon wird nur einen Teil von etwa 8000 Hektar bewirtschaftet (Produktionszentrum Erlau). Die beiden Weinsorten, die zur Zeit in größter Menge verkauft werden, sind wie folgt Erlauer Stierblut (Egri bikavér - Rotwein) und Erlauer Stern (Egri csillag - Weißwein). (Gál - Gál, 2014) Das Brand verknüpft sich sehr bewußt mit der historischen und literarischen Tradition (vgl. oben: militärischer Sieg der Ungarn gegen die Türken im Jahr 1552 und der berühmte Roman von Gárdonyi). Einen ähnlichen Image-Bauprozess kann im Fall des Weines Bakator auf der rumänischen Seite nicht identifiziert werden.

Seit der Wende verfahren die Winzerinnen und Winzer in Erlau bewußt: Immer mehr Berufsveranstaltungen werden organisiert, wo u.a. Hauptthemen wie Weintechnologie und Weinkultur diskutiert werden. Neben theoretischen Ausführungen spielen im Wirtschaftsleben der Stadt auch die populären Veranstaltungen eine große Rolle, wo die Sinnesorgane im Spiel sind (Weinfestivals, Weinbälle, massenhaftes und öffentliches Verschenken von Wein statt herkömmlichen Weinproben usw.). Diese Programme wiederholen sich regelmäßig 
in bestimmten Zeitpunkten des Jahres, sie können also in Familienkalendern aufgenommen und rechtzeitig geplant werden. Seit der Jahrtausendwende werden Weinveranstaltungen immer mehr mit kulinarischen Begleitprogrammen ergänzt. Die größte Tandemveranstaltung für Wein- und Gastrokultur in Erlau (Egri Bikavér Ünnep = Fest des Erlauer Stierbluts) findet jedes Jahr in der zweiten Juliwoche statt. In der Region Partium und in Großwardein spielen sich solche Veranstaltungen meistens noch ohne Tradition ab, aber einige Tendenzen oder die Absicht zur Traditionsgründung scheinen schon ab und zu wahrzunehmen.

\section{Lebendige Tradition}

Touristen anlockend können auch die überlieferten Gebräucheund dieanschließenden kulturellen Programme wirken. Die Elemente der lebendigen Tradition sind immer stark an Lokalpatriotismus angefesselt. Die Zuneigung zum historischen Sittensytem der eigenen Stadt Erlau erscheint in der Aufbewahrung und Weitergabe der sog. Viertelmeisterwürde (fertálymesterség) in dominanter Weise. Diese frühere Funktion und heutige Tradition lebt seit mehr als dreihundert Jahren - parallel zu anderen europäischen Siedlungen, wo deutschsprachige Bürger wohnten - in der ungarischen Stadt weiter. Das Amt der Viertelmeister wurde spätestens im letzten Drittel des 19. Jahrhunderts überall in Europa eingestellt, aber in Erlau funktionierte es bis 1950 weiter. Nach einer Zäsur zwischen 1950 und 1995 wurde es als traditionspflegerische Bewegung wieder ins Leben gerufen. Heute leben etwa vierhundert emeritierte Viertelmeister in Erlau und bilden die Mitgliedschaft der größten Zivilorganisation der Stadt. (Petercsák, 2014) Sie vertreten sich an allen städtischen Veranstaltungen konsequent. Ihre Programme sind bei den Stadtbewohnern und den Touristen sehr attraktiv. Hier geht es um einen sich seit dreihundert Jahren organisch entwickelnden Lokalpatriotismus, was als ganz eigenartig gilt.

Das lokalpatriotische Gefühl der Rumänienungarn, das sich im Rahmen der Kulturwochen des sog. Festum Varadinum (Mai) und der St.-Ladislaus-Tage (Juni) zeigt, findet in der mittelalterlichen Geschichte von Großwardein ihre Wurzeln, aber die Veranstaltungen wurden erst - nach einer Zäsur von 50 Jahren - 1992 (FV) bzw. - als Neugründung - 2013 (SLT) ins Leben gerufen. (Jósa, 2009) Die rumänische Bevölkerung der Stadt schloss sich den Veranstaltungen des Festum Varadinum ziemlich spät an, jedoch mit eigenem Lokalpatriotismus von einem ganz anderen Charakter, der seine Anfänge in der Epoche zwischen den beiden Weltkriegen findet und ist stark vom Nazionalismus geprägt. Als Folge der scharf abweichenden Geschichtsauffassungen beider Nationalitäten kann die nationalistisch gesinnte Praxis der "Raumverwendung" bzw. die der "Platzeinnahme" oder "Platzbesetzung" öffentlicher Räume genannt werden. Der Unterschied der ethnisch-kulturellen Identitäten äußert sich auch im neuen rumänischen Kulturfest "Großwardeiner Herbst" (Oradea Festifall), das sich in das lokale kulturelle Leben ziemlich schnell einfügte. (Kormányos, 2019) 
Die oftgar nicht harmlosen Auseinandersetzungen zwischen Rumänen und Ungarn im Rahmen der kulturellen Veranstaltungen wirft eine wichtige Frage des Rechts zum Kulturerbe auf. Abgesehen von den "allgemeinen”, täglichen Feindseligkeiten der Nationalitäten scheint das Phänomen der sog. „Ersitzung” des kulturellen Erbgutes immer konkreter zu sein. Das bedeutet ganz einfach, dass das kulturelle Erbe der Ungarn vom die Mehrheit bildenden Rumänentum ersitzt oder enteignet wird. Die ethnische-sprachliche Minderheit der Ungarn erstrebt demgegenüber standhaft, ihre nationale und lokale Kultur, ihr örtliches Erbgut darzustellen, weil all das als Kraft für die Aufrechterhaltung ihrer Gemeinschaft betrachtet wird. Diese Auffassung hat immerhin eine Vorgeschichte in der protestantischen Weltanschauung im Osten des Donau-Karpatenraumes, die sich vom orthodoxen Bekenntnis von byzantinischem Ritus grundsätzlich unterscheidet.

\section{Fragezeichen in der touristischen Strategie und dem Destinationsmanagement}

Im vorliegenden Beitrag wurden Verwendungsstrategien für das kulturelle Erbgut kurz geschildert, die in zwei, sich geschichtlich parallel entwickelnden Städten in Rumänien und Ungarn zur Geltung kommen oder gebracht werden sollten. Anhand dessen sollten einige Dilemmas erwähnt werden.

Erstens: WaswäreeineguteStrategiebei der Planung des Destinationsmanagements, um die Kultur zugänglich und nutzbringend zu machen? Müssten Lokalpatriotismus oder Universalismus in den Vordergrund gestellt werden?

Zweitens: Locken die Elemente des örtlichen oder des nationalen kulturellen Erbgutes mehr Touristen in die Region an? Sollte eventuell versucht werden, die eigene Kultur unter dem prestigeträchtigen Titel des Weltkulturerbes anerkennen zu lassen, um daraus einen möglichst hohen Geschäftsgewinn zu ziehen?

Drittens: Was bringt mehr Nutzen für die Region, die Förderung der kulturellen Autonomie oder die Popularisierung des Kosmopolitismus? Diesbezüglich eine kurze Anmerkung zur kulturellen Lage der Rumänienungarn in Großwardein: Sie bekamen nach 1989 eine kulturelle Autonomie. Sie konnten ihre kirchlichen und weltlichen Unterrichts- bzw. kulturelle und Pressesysteme (Szigligeti-Theater, Bunyitay-Bibliothek, Ernő-Tibor-Galerie, Christliche Universität "Partium” usw.) wieder beleben und öffentliche kulturelle Veranstaltungen organisieren, die das Rumänentum allmählich zu ersitzen scheint. In Erlau existiert diese Situation in einem vorrangig ungarischen Milieu selbstverständlich nicht.

Viertens: Was wäre günstiger? Den Tourismus auf die Personen der eigenen Nationalität zu richten oder die von der Nationalität unabhängigen Tourismuszweige 
zu verstärken? Im ersten Fall kommen die Elemente des eigenen, lokalen, geistigkulturellen und gebauten Erbgutes zu Wort, im anderen Fall sollten Gastro-, Wein-, Heil-, Gesundheits-, Wellness-, Einkaufs- und Konferenztourismus usw. gefördert werden. Der Religionstourismus kann eine überbrückende Rolle in diesem Problemfeld spielen.

Fünftens: Braucht man in der Strategie ein einfaches Portfolio oder ein komplexes touristisches Angebot? Jede historische Epoche hat ihre Spuren in den Städten, auf den öffentlichen und privaten Gebäuden, in der Siedlungsstruktur (Anordnung der Straßen und Plätze), in den Kirchen und hoffentlich auch in den Köpfen der dort lebenden Menschen hinterlassen.

\section{Fazit}

Aus den fünf Punkten zeichnen sich eine weitverzweigte Geschichte und eine zusammengesetzte Vergangenheit ab, was auf den ersten Blick ein komplexes touristisches Angebot darstellt. Das Portfolio und die Stichwörter in den Werbungen sollten aber ganz einfach und unkompliziert sein. Die Touristen können nämlich nur mit Hilfe von klaren, eindeutigen und wenigen Schlagwörtern wie z.B. Kultus, lebendige Tradition, Wein- und Gastrokultur, Badekultur u. dgl. mobilisiert und in die Region gelockt werden! Das dichte, übertriebene Portfolio kann auf die Touristen in den meisten Fällen abstoßend wirken. Eine Komplexität der Programme oder Attraktionen kann man immer vor Ort, wenn die Besucher schon da sind, anbieten.

Zum Schluss kann festgestellt werden, dass die kulturellen und ökologischen Erbgüter ausschließlich in dem Fall einen wirtschaftlichen Nutzen bringen können, wenn sie wirklich genutzt sind. Und die Nutzung sollte durch sämtliche Gesellschaftschichten der Bevölkerung und alle Nationalitäten auf Grund der Parität geschehen. Dieses gemeinsame Nutzen von Kulturgütern kann selbstverständlich nicht nur in Hinsicht auf die Nationalität verwirklicht werden, sondern es kann auch auf geographischen Grundlagen ruhen. Es wäre sehr nützlich, für beide Destinationen gleichzeitig eine Imagewerbung durchzuführen und die Besucher der einen Region in die andere Destination umzuleiten, indem ihr Interesse und Augenmerk auf die Kulturgüter der anderen potentiellen, attraktiven touristischen Zielpunkte gelenkt werden. So würde die historische Interdependenz in Form einer gegenseitigen Abhängigkeit in der Gegenwart wieder lebendig. 


\section{Hivatkozott források}

[1.] Cséplő P. (1901): Bihar vármegye és Nagyvárad őskora. In: Borovszky S. (Hg.): Bihar vármegye és Nagyvárad. Budapest, "Apolló" Irodalmi Társaság, S. 444-454. (Magyarország vármegyéi és városai); Reiszig E.: Bihar vármegye története. A legrégibb időktől a Mohácsi vészig. In: Borovszky S. (Hg.): Bihar vármegye és Nagyvárad. Budapest, “Apolló” Irodalmi Társaság, S. 454485. (Magyarország vármegyéi és városai); Nagy J. (1978): Eger története. Budapest, Gondolat, S. 9-14.; Vahot I. (21985): Eger története a legrégibb időktől az 1551-ki ostromig. In: Kubinyi F. - Vahot I. (Hg.): Magyarország és Erdély képekben. Bde 3-4. Budapest, ÁVK, S. 1-6.

[2.] Bunyitay V. (1883): A váradi püspökség története. Bd. I. Nagyvárad, Római Katolikus Egyházmegye, S. 29-44.; Kristó Gy. (1988): A vármegyék kialakulása Magyarországon. Budapest, Magvető, S. 474-482.

[3.] Hankó I. (2004): Királyaink tömegsírban. A Magyar királysirok sorsa Géza fejedelemtöl Szapolyai Jánosig. Budapest, Magyar Ház, verstreut.

[4.] Bunyitay V. (1883): A váradi püspökség története. Bd. I. Nagyvárad, Római Katolikus Egyházmegye, verstreut; Sugár I. (1984): Az egri püspökök története. Budapest, Szent István Társulat, verstreut; Kovács B. (1987): Az egri egyházmegye története 1596-ig. Eger, Egri Főegyházmegyei Érseki Iroda, verstreut.

[5.] Fraknói V. (1888): Ipolyi Arnold emlékezete. Budapest, Hornyánszky Ny.; Gyalókay J. (1937): Olasz várépítők Magyarországon a XVI-XVII. században. In: Magyar Szemle, 30. Jg., Nr. 5-8., S. 288-296.; Szmrecsányi M. (1937): Eger müvészetéröl. Tanulmányok és jegyzetek a hazai barokk történetéhez. Budapest, Stephaneum; Tarr I. (1977): Iskola és művelődés a középkori Nagyváradon. In: Müvelödés, 30. Jg., Nr. 2., S. 28-30., Nr. 3., S. 19-21., 51-53., Nr. 6., S. 17-19., Nr. 7., S. 42-44.; Péter I. Z. (1998): Nagyvárad épitészeti emlékei a barokktól a szecesszióig. Nagyvárad, Convex; Emődi A. (2010a): Nagyvárad város lakossága és archontológiája a 18. században (1713-1785). Nagyvárad, Varadinum Script. (Miscellanea Historica Varadiensia; 2); Emődi A. (2010b): Adatok Nagyvárad 18-19. századi patika- és kórháztörténetéhez. In: Erdélyi Múzeum, 72. Jg., Nr. 3-4., S. 163-184.; Boka L. - Emődi A. (Hg.) (2016): Tipográfia régtöl fogva. A nagyváradi nyomdászat 450 éves története. Budapest, Országos Széchényi Könyvtár, Argumentum Kiadó; Emődi A. (2017): Még egyszer a nagyváradi patikák kezdeteiről. In: Kaleidoscope, 8. Jg., Nr. 14., S. 149162., letzter Zugriff: 6. Mai 2020, Quelle: http://www.kaleidoscopehistory. hu/index.php?subpage $=$ cikk\&cikkid $=329$ 
[6.] Bunyitay V. (1880): A nagyváradi latin szertartású székesegyház. Nagyvárad, Római Katolikus Egyházmegye; heute mit eigener DenkmalschutzHomepage: http://lexikon.adatbank.transindex.ro/muemlek.php?id=264, letzter Zugriff: 6. Mai 2020

[7.] Voit P. (1934): Az egri föszékesegyház. Eger, Egri Keresztény Sajtószövetkezet Könyvkereskedés; heute mit eigener Homepage: http://www.eger-bazilika. plebania.hu/, letzter Zugriff: 6. Mai 2020

[8.] Kiss G. ( $\left.{ }^{2} 1990\right):$ Erdélyi várak, várkastélyok. Budapest, Panoráma, S. 63-73.

[9.] Sugár I. (32002): Az egri vár históriája. Budapest, Zrínyi.

[10.] Petercsák T. (2002): Az egri vár kultusza. In: Honismeret, 30. Jg., Nr. 5., S. 7-14., letzter Zugriff: 6. Mai 2020, Quelle: https://epa.oszk.hu/03000/03018/00170/ pdf/EPA03018_honismeret_2002_05_007-014.pdf

[11.] Balla T. - Lakatos A. (Hg.) (2013): “Várad várának, az pogány török által megh szállásárul..." Szalárdi János emlékirata Várad 1660. évi veszedelméröl. Budapest, Nagyvárad, Országos Széchényi Könyvtár, Partium Kiadó.

[12.] Fleisz J. (2003): Nagyvárad tudós püspökei. Nagyvárad, Partiumi és Bánsági Műemlékvédő és Emlékhely Bizottság, Királyhágómelléki Református Egyházkerület, Nagyváradi Római Katolikus Püspökség.

[13.] Löffler E. (22002): Két és fél évszázad az egri püspökök és érsekek történetéböl, 1699-1943. Eger, Érseki Gyüjteményi Központ.

[14.] Haris A. - Somorjay S. - Bardoly I. (Hg.) (2005): Magyarország müemlékjegyzéke - Heves megye. Budapest, Kulturális Örökségvédelmi Hivatal.

[15.] Dukrét G. - Péter I. Z. (2016): Nagyvárad és Bihar megye épitett öröksége. Nagyvárad, Partiumi és Bánsági Müemlékvédő és Emlékhely Társaság.

[16.] Pomogáts B. (2013): Kis nagyváradi magyar irodalomtörténet. Erschienen am 28. Februar 2013. Letzter Zugriff: 6. Mai 2020, Quelle: http://www.varad. ro/kis-nagyvaradi-magyar-irodalomtortenet/

[17.] Hovanyecz L. (2005): Eger két írócsillaga: Bródy Sándor és Gárdonyi Géza. Eger, Eger Város Önkormányzata.

[18.] Bede B. (2014): Gyógyfürdök és gyógyszállók Magyarországon. Budapest, Corvina, anschließende Teile.

[19.] Péter I. Z. (2009): A Nagyvárad melletti termálfürdők rövid története. In: Korunk, 20. Jg., Nr. 8., letzter Zugrif: 6. Mai 2020, Quelle: https://epa.oszk. hu/00400/00458/00152/index4c0d.html 
[20.] Duka I. L. (2005): Érmelléki szőlőkultúra, borászat. In: Veliky J. (Hg.): Érmellék. Egy kistérség rekonstrukciója. Debrecen, Hatvani István Szakkollégium, S. 115-126., letzter Zugriff: 6. Mai 2020, Quelle: http:// biharkutatas.hu/wp-content/uploads/2012/01/em104.pdf; Fazekas M.-F. (2020): Az érmelléki szölészet és borászat. Erschienen am 11. Januar 2020, letzter Zugriff: 6. Mai 2020, Quelle: http://mnyknt.hu/2020/01/11/azermelleki-szoleszet-es-boraszat/

[21.] Gál L. - Gál T. (2014): Az egri bor - Bikavértöl a Csillagig. Eger, Líceum Kiadó.

[22.] Petercsák T. (2014): A fertálymesterség. Egy hagyományőrző tisztség Egerben. Budapest, Eger, Kossuth, Líceum Kiadó. (Kulturális örökség; 5)

[23.] Jósa P. (2009): Árpádházi királyok kései találkozója Nagyváradon. Az 1942 es Szent László ünnepi hét krónikája. Nagyvárad, Hatvannégy Vármegye Ifjúsági Mozgalom.

[24.] Kormányos L. (2019): Nagyvárad krónikája. Nagyvárad, Varadinum Alapítvány, verstreut. Das stattliche Buch gibt im Allgemeinen wissenswerte Informationen zu jedem Themenkreis, der in diesem Beitrag mit Bezug zu Großwardein erwähnt worden sind.

* Die Forschung wurde im Rahmen des Projektes EFOP-3.6.1-16-2016-00001 „Komplexe Entwicklung der Forschungskapazitäten und-dienstleistungen an der Károly-EszterházyUniversität" gefördert.

\section{Dr. habil Attila Verók}

Lehrstuhlleitender Universitätsdozent

Károly-Eszterházy-Universität (Eger)

Institut für Geschichtswissenschaft

Lehrstuhl für kulturelles Erbe und Kulturgeschichte verok.attila@uni-eszterhazy.hu

und

Universitätsdozent

Christliche Universität "Partium” (Oradea)

Lehrstuhl für ungarische Sprache und Literatur verok.attila@partium.ro 